\title{
El neoliberalismo en acto: políticas sociales y experiencias organizativas en Argentina (2009-2016)
}

\author{
Ana Natalucci \\ CONICET. Universidad de Buenos Aires, Buenos Aires, Argentina. \\ Email: anatalucci@gmail.com
}

\begin{abstract}
Resumen:El neoliberalismo es un proceso enrevesado de transformación socio-espacial, ni unívocamente de "arriba hacia abajo” ni de “abajo hacia arriba”; se trata de un discurso donde se fusionan las dimensiones estructurales y agenciales. El objetivo del artículo esanalizar una política social implementada en Argentinadesde 2009: el Programa Ingreso Social con Trabajo.Su indagación permite comprender cómo opera el discurso neoliberal en términos de sus efectos como en las transformaciones en la agencia de los actores sociales. Siguiendo una perspectiva cualitativa, la hipótesis planteada es que aún con el discurso neoliberal, el PRIST se constituyó en una oportunidad para el reconocimiento de los trabajadores informales y para las organizaciones al permitirles reposicionarse como sus representantes. El neoliberalismo atraviesa los diferentes ámbitos sin por esto aplastar la capacidad propositiva de los actores sociales. Las nuevas experiencias organizativas nos hablan acerca de cómo se construyen los vínculos entre neoliberalismo, política y ciudadanía.
\end{abstract}

Palabras claves: Discurso neoliberal, empleabilidad, economía popular, PRIST, CTEP

\section{Neoliberalism in Action: Social Policies and Organizational Experiences in Argentina (2009-2016)}

\begin{abstract}
Neoliberalism is a confusing process of socio-spatial transformation, which is neither a 'top-down' nor a 'bottom-up' phenomenon. It is a discourse where the structural and agency dimensions merge. The aim of this paper is to analyze a social policy implemented in Argentina since 2009: the Programa Ingreso Social con Trabajo (PRIST). This allows us to understand how neoliberal discourse operates in terms of its effects as well as in the transformations regarding the agency of social actors. Following a qualitative perspective, the hypothesis is that even within the neoliberal discourse, PRIST constituted an opportunity for the recognition of informal workers and its organizations by allowing them to reposition themselves as their representatives. Thus, neoliberalism crosses the different areas without crushing the proactive capacity of social actors. The new organizational experiences tell us about how the links between neoliberalism, politics and citizenship are built.
\end{abstract} CTEP

Keywords: neoliberal discourse, employability, popular economy, PRIST, 


\section{O neoliberalismo em ato: políticas sociais e experiências organizativas na Argentina (2009-2016)}

Resumo: O neoliberalismo é um processo intrincado de transformação socio-espacial, nem univocamente "de cima para baixo" nem "de baixo para cima”; trata-se dum discurso onde se fusionam as dimensões estruturais e de agência. $\mathrm{O}$ objetivo do artigo é analisar uma política social executada na Argentina desde 2009: o Programa Renda Social com Trabalho. Sua indagação permite compreender como opera o discurso neoliberal em termos de seus efeitos como nas transformações na agência dos atores sociais. Seguindo uma perspectiva qualitativa, a hipótese proposta é que ainda com o discurso neoliberal, o PRIST se constituiu numa oportunidade para o reconhecimento dos trabalhadores informais e para as organizações porque lhes permitiu reposicionar-se como seus representantes. O neoliberalismo atravessa os diferentes âmbitos sem por isso esmagar a capacidade propositiva dos atores sociais. As novas experiências organizativas nos falam de como se constroem os vínculos entre neoliberalismo, política e cidadania.

Palavras chave: Discurso neoliberal, empregabilidade, economia popular, PRIST, CTEP

\section{Introducción}

El neoliberalismo adquirió una amplia polisemia, puede referir a un proyecto ideológico hegemónico, a un programa político, una forma estatal o un modo específico de gubernamentalidad (Springer, 2012). Movimientos sociales usandicha palabra como adjetivo de las políticas que pretenden revertir los derechos instaurados durante el Estado de Bienestar. Para algunos dirigentes políticos y jefes de Estado significa una barrera a partir de la cual buscan construir legitimidad para ellos y sus proyectos políticos. En estos usos se instituyó una familia de palabras, contraneoliberal, neoliberalización, para precisar ciertos procesos que de otra manera serían englobados, y por eso también desdibujados, bajo la etiqueta neoliberal (Brenner, Pecky Theodore, 2010). Incluso, los gobiernos de principios del actual siglo fueron denominados posneoliberales (Sader, 2009; Grugel y Riggiorizzi, 2012).

Parala perspectiva de la geografía crítica y la economía política, el neoliberalismo implica un nuevo consenso que buscaba desmontar el Estado de bienestar a partir de la implementación de un conjunto de políticas ortodoxas, como disciplina fiscal, libre mercado y libre comercio, la privatización de los servicios públicos ${ }^{1}$.Parala perspectiva foucaultiana,constituye una forma de gubernamentalidad,entendida como el arte de gobernar, una práctica orientada a la "mejor forma posible" de gobierno. Estaimplica "estudiar la racionalización de la práctica gubernamental en el ejercicio de la soberanía política”(Foucault, 2004, p. 17), en tanto cada una de estas prácticas“produce sus propias tecnologías de poder y racionalidad política” (Lemke, 2000, p. 2). Ambas perspectivas acuerdan en que el neoliberalismo supone la expansión de la lógica de la 
mercantilización en todos los ámbitos de la vida político-económica implicando el desdibujamiento de la diferencia entre las racionalidades económica y política (de Lagasnerie, 2012) ${ }^{2}$ y, fundamentalmente, reordenando las relaciones entre Estado, mercado y sociedad civil. La sociedad civilya no se piensa como una red asociativa de sujetos de derechos, sino como una trama molecular de empresas en competencia (Pérez, 2011).

Springer (2012) sostiene que el neoliberalismo no es únicamente un fenómeno de “arriba hacia abajo” ni de "abajo hacia arriba”, sino un proceso enrevesado de transformación socio-espacial. Se trata de un discurso donde ambas perspectivas quedan fusionadas. La potencialidad analítica de esta propuesta radica en considerar la dimensión estructural y agencial como los discursos y las prácticas.Esta perspectiva supone dos implicancias. La primera es que el neoliberalismo es constitutivo y constringente pero no determinante; la segunda es que -como cualquier discurso- no tiene los mismos efectos en cualquier lugar (Ibid, p. 139-140. Traducción propia). De ahí la importancia de analizar sus variaciones específicas en situaciones y prácticas coyunturales, en definitiva, se trata de indagar sobre "el neoliberalismo realmente existente” (Springer, 2012). La consideración de la estructura y la agencia implica ahondar en cómo se moldean formas de intervención social y los modos en que los agentes toman un "papel proactivo en la remodelación de las prácticas formales de política, política y administración” (Ibid, p. 142).

A los fines de este artículo, el neoliberalismo constituye un discurso capaz de configurar campos de acción, donde prima la lógica de la mercantilización y una concepción de sociedad civil caracterizada por la individuación, la autogestión, la autorregulación, sobre la base del empoderamiento. Este último concepto, asociado al capital social, remite a "los procesos de aprendizaje de capacidades personales que se obtienen y se vuelcan en la actividad grupal, con el consecuente crecimiento organizativo” (Papalini y Natalucci, 2005, p. 206-207). A su vez, el empoderamiento "subraya la dimensión de autorrealización y aprendizaje en las prácticas de gestión y organizaciones de grupos, de toma de la voz, de capacitación y participación” (Ibid, p. 206). La adquisición de esta capacidad individual se orienta a la "búsqueda de una solución biográfica a problemas sistémicos”(Ibid, p. 206). De esta manera, el neoliberalismo no sólo afectó la fisonomía de la estructura socio-económica marcando una división entre sectores integrados y no integrados, sino tambiénlos sentidos políticos impregnados en el Estadoyen la agencia de los actores sociales.

Con este breve marco, el objetivo de este artículo no es realizar un exhaustivo análisis sobre el neoliberalismo, sino estudiar un caso a modo de ejercicio analítico para comprender cuál es su operatoria en términos de efectos (racionalidades, tecnologías y estrategias) ylastransformaciones en la dimensión agencial de los actores sociales. Concretamente, se tomará una política social implementada por el gobierno de Cristina Fernández de Kirchner en Argentina: el Programa Ingreso Social con Trabajo (PRIST). Una política social constituye un modo en que el Estado se propone inter- 
venir en la sociedad. La selección del PRIST se justifica en tanto condensa una serie de tensiones acerca de cambios societales, el tipo de intervención estatal y la resignificación de la agencia.El recorte temporal se extiende entre 2009, momento de implementación, hasta 2016 momento donde el PRIST sufrió sumas modificaciones por el gobierno de Cambiemos.

Desde una concepción pragmática, comprender una política social implicaconsiderar su formulación e indagar qué hacen los actores sociales con ella. Siguiendo una perspectiva cualitativa, la hipótesis que ordena la exposición es la siguiente: del lado de la formulación institucional,el PRIST tuvo una lógica neoliberal que combinó, por un lado, criterios de focalización y selectividad orientados a sectores considerados inempleables y, por otro,un perfil socio-producto que promovía la individualización, la autogestión, la autorregulación; del lado agencial el PRIST se constituyó en una oportunidad para el reconocimiento de los trabajadores informales y la creación de una representación por parte de las organizaciones.En este sentido, aunque el neoliberalismo como discurso atraviese los diferentes ámbitos e impregne de ciertos sentidos a la lógica estatal, los agentes hacen uso de su capacidad propositiva para leerlo como una oportunidad. Al respecto, las nuevas experiencias organizativas tienen mucho para decirnos acerca de cómo se construyen los vínculos entre neoliberalismo, política y ciudadanía. ${ }^{3}$

\section{Breve historia sobre las políticas sociales}

Hasta mediados de los setenta, en Argentina la política social era marginal respecto de la acción estatal, su orientación estaba ligada a sectores que tenían algunas carencias en el marco de una sociedad caracterizada por un empate hegemónico (Svampa, 2005).Su despliegue siguió un ritmo inverso a la desestructuración del mundo del trabajo y las protecciones sociales;a la lógica caracterizada por la universalidad de los derechos le siguió una de programas focalizados y enlatados (Massetti, 2011). Los ciudadanos receptores de esas políticas fueron denominados beneficiarios y su principal fuente de financiaciónproveníade los organismos multilaterales de crédito.

Durante los noventa, el gobierno nacional presidido por Carlos Menem impulsó un proceso de reconfiguración estatal, que trastocó la institucionalidad preexistente tanto en la estructura burocrática como en la agencia de los actores sociales. Si bien esto sucedió en muchos países, en Argentina cobró importancia debido al proceso de incorporación de los sectores populares a la comunidad política a través de mediaciones corporativas como los sindicatos (Collier y Collier, 1991). Esta transformación se reflejó en la consigna "la nueva fábrica es el barrio", que marcaba la reconfiguración del mundo fabril y la creciente importancia que cobraban los territorios por el crecimiento de las organizaciones sociales. Estas fueron claves en la expansión de la estrategia de auto-organización de los sectores populares en la resolución colectiva de sus necesidades básicas. 
Entre las consecuencias, el gobierno amplió los espacios de decisión de los actores territoriales acercando los destinatarios a las acciones (Arias, 2013) y decidió en 1999 la conversión de la secretaría Desarrollo y Acción Social -dependiente del Ministerio de Salud y Acción Social- en un ministerio de dedicación exclusiva a la "nueva cuestión social” (Rossi, 2017). Ambas transformaciones fueron acompañadas por un nuevo lenguaje: empoderamiento, capital social, libre iniciativa, autoempresarialidad, autogestión y responsabilidad sobre sí (Gago, 2014). Estas consecuencias dejan entrever la difusión de las ideas neoliberales impulsadas por un colectivo heterogéneo que reunía dirigentes políticos, grupos empresarios, intelectuales con base en fundaciones y consultoras con contactos con los organismos multilaterales de crédito (Morresi, 2011). Una de las mayores novedades de este ciclo se trató de la resignificación del derecho a la asistencia: si en el modelo estatal bienestarista toda persona por el hecho de ser ciudadano tenía derecho a ser asistido, en el neoliberal la persona se encontraba en deuda con la sociedad que debíacancelar medianteuna contraprestación (Castel, et. al., 2013).

Ese ciclo de reconfiguración societal, que derivó en la crisis de legitimidad de 2001en un sentido weberiano, fue seguido por otro, llamado"giro a la izquierda" (Levitsky y Roberts, 2011)“marea rosa” (Álvarez, et. al, 2017) o "posneoliberal” (Sader, 2009; Grugel y Riggiorizzi, 2012). El nuevo ciclose produjo en el marco de las presidencias kirchneristas (Néstor Kirchner, 2003-2007, Cristina Fernández de Kirchner 2007-2015), donde se conjugaron políticas económicas heterodoxas, un cambio de paradigma con la sociedad y la construcción de un discurso contra el neoliberalismo que se pronunciaba a favor de "más Estado y menos mercado".Esta idea tuvo una profunda resonancia en aquellos sectores que habían padecido la desarticulación del mundo del trabajo, del sistema de protecciones sociales yel retraimiento de las formas organizativas tradicionales.

En el nuevo ciclo, las mayores transformaciones tuvieron relacióncon la restauración de las políticas laborales, de la seguridad social y en los vínculos entre el Estado y las organizaciones. Esta última se reflejó en la recreación de la gramática movimentista de acción colectiva que articuló una elite política (integrada por sectores del Partido Justicialista) con unheterogéneo conjunto de organizaciones sociales y sindicales, protagonistas delas luchas contra el neoliberalismo. Por ello, el kirchnerismo significó, al mismo tiempo, una posibilidad identificatoria y una oportunidad estratégica que permitió que las organizaciones dejaran elroleminentemente anclado en la construcción territorial y decidieran un salto a la política consistente en la participación en los poderes ejecutivo y legislativos y en la implementación de políticas sociales (Natalucci, 2015). ${ }^{4}$ En este marco es que deben comprenderse los cambios en materia de políticas sociales. 


\section{La política social durante el kirchnerismo: entre la integración y la inclusión}

En 2004,Kirchner prorrogó la ley de Emergencia Ocupacional Nacional y decidió la reformulación de la política social en términos de la promoción de la cultura del trabajo, la reinserción laboral de los beneficiarios y su atención específica en caso de mayor vulnerabilidad. ${ }^{5}$ Es destacable que esta decisión sostuvo como válido el criterio de empleabilidad, que clasificabaa la población beneficiaria en dos grupos: empleable y no empleable (Scarfó, Hopp y Highton, 2009). El primero estaba compuesto por quienes debido a sus trayectorias laborales individuales tenían capacidad para conseguir un empleo en un marco de reactivación económica; el segundo incluía a aquellos quepor esas mismas cuestiones quedaban fuera del mercado. Estecriterio había sido formulado por la OIT para resaltar las competencias y capacidades personales que permiten a los individuos "aprovechar las oportunidades de educación y de formación con miras a encontrar y conservar un trabajo decente, progresar en la empresa o al cambiar de empleo y adaptarse a la evolución de la tecnología y de las condiciones del mercado de trabajo” (2005, p. 4).Bajo este criterio, se reorganizó el tipo de intervención estatal y se redistribuyeron los Planes Nacionales. ${ }^{6}$ La conservación de este criterio por parte del gobierno kirchnerista demuestra la pregnancia deldiscursoneoliberal en la política social y constituye una continuidad respecto del ciclo anterior.

Las continuidades o rupturas de la política social entre los ciclos neoliberal y posneoliberal son objeto de controversia. García Delgado sostiene que el kirchnerismo ha producido “un cambio estructural”(2011, p. 55), donde caracterizaa lapolítica social de segunda generación a partir de suestrategia neo universalista frente a la focalización, su orientación a la inclusión antes que a la contención. El autor destacala asociación entreempleo, dimensión productiva y elcambio significativo en la relación con los movimientos sociales, queimplicósu creciente incidencia en la formulación e implementación de la política social. En cambio, Lo Vuolo sostiene que la política social del kirchnerismo "corporiza un modo de regulación de la cuestión social que [ha demostrado] ser inadecuado e ineficaz (2010, p. 2). Para el autor, el PRIST constituye "un programa asistencial de empleo forzado” (Ibid, p, 5). Como alternativa a esta disyuntiva, Massetti (2011) o Kessler (2014) se han interesado por los claroscuros, continuidades y desplazamientos entre ambos ciclos. ParaMassetti(2011) programas como el PRIST constituyen una política social de tipo asistencial,aunque inscripta en un proceso de ampliación del sistema de protección social. En otras palabras, se trata de una política transitoria y focalizada, pero al estar combinada con otrasuniversales ha logrado mayor impacto sobre la población beneficiaria. En esta última perspectiva es que nos interesa analizar el PRIST tanto en su dimensión normativa como agencial. 


\section{La apuesta por la inclusión}

Los años 2008 y 2009 constituyeron un punto de inflexión por la crisis económica internacional y por la derrota del gobierno en los comicios de medio término. Si bien a nivel nacional los resultados fueron heterogéneos, el oficialismo tuvo un mal desempeño en la provincia Buenos Aires, cuya representación alcanza alrededor del 30\% del padrón electoral. Según datos proporcionados por Arcidiácono, Kalpschtrej y Bermúdez (2014), a mediados de 2009, el debate público en torno a la pobreza, la desocupación y la informalidad había cobrado la misma intensidad que en los meses posteriores a la crisis 2001.Para 2009, el porcentaje de la población bajo la línea de pobreza se calculaba en torno al $32 \%$ y si bien era bastante menos que el $57 \%$ de 2002 era más elevado que el 27\% de 2005. ${ }^{7}$ El gobierno atribuyó la derrota al estancamiento económico como resultado de la crisis, mientras las organizaciones kirchneristas evaluaban que no todos los sectores habían sido beneficiados por la creación de empleo y la reactivación (Natalucci, 2012a). Por su parte, Emilio Pérsico, dirigente del Movimiento Evita, manifestó "la necesidad de crear un millón de puestos de trabajo, que permitieranmejorar las condiciones de vida de millones de personas y revertir la fragmentación de la clase trabajadora en términos de sus condiciones laborales, salariales y políticas” (Ibid, p. 138). ${ }^{8}$ Siguiendo esta posición, la creación de trabajo no dependía del sector privado, sino de que el Estado subsidiara cooperativas de trabajo.

A efectos de la intervención estatal,la idea que había sectores que no estaban intergrándose al proceso económico, más la presión de las organizaciones, marcó un punto de inflexión. Al respecto, el gobierno tomó una doble decisión: los programasno podían seguir bajo la lógica de la transitoriedad y la creación demecanismos de compensación para los sectores “inempleables”. Por ello, en agosto de 2009, el gobierno impulsó el PRIST por medio del decreto $\mathrm{N}^{\circ} 1067 .{ }^{9}$ Durante el acto de lanzamiento, Fernández de Kirchner mencionó que "El problema en la Argentina no [era] la pobreza sino la inequidad social”. ${ }^{10} \mathrm{En}$ su discurso, admitió que un importante sector social no podía ser integrado con derechos plenos por lo que requería de una acción directa vía promoción estatal del empleo bajo la forma de cooperativas. En coincidencia con esta posición, elMDS publicó una serie de documentos con los fundamentos del programa, entre ellos que estaba orientado a la "generación de trabajo genuino [destinado] a aquellos sectores que [...]no han logrado incorporarse al mercado de trabajo formal” (Ibid, 2010, p. 3); y que pese al "importante proceso de crecimiento económico" y al despliegue de "herramientas de política social” aún existía un núcleo duro de desocupados, que producto de un largo "proceso de exclusión requiere de la intervención decidida y sostenida del Estado" (Ibid, 2010, p. 3). Es cierto quela justificación gubernamental del PRIST remitía a la creación de empleo más que a una nueva política social, sin embargo cuando se profundiza en su formulación e implementación pueden observarse algunos matices.A priori, desde la perspectiva del MDS, el PRIST debía conformarse en una herramienta orientada al desarrollo local y la economía social, "promoviendo el desarrollo de capital humano y capacidades sociales de 
personas en situación de alta vulnerabilidad socio- económica a través de la generación de oportunidades socio-ocupacionales” (2014, p, 6).

\section{EI PRIST como oportunidad}

Esta redefinición de la política social apareja algunos interrogantes:¿qué significa que la creación de empleo sea por medio de la economía social, básicamente por cooperativas? ¿Cuáles son las implicancias que estas sean creadas por un ministerio estatal y no por los parámetros clásicos del cooperativismo? La economía social ya era un lineamiento importante en las políticas sociales del kirchnerismo, y contaba con antecedentes, por ejemplo los programas"Manos a la Obra" ${ }^{11}$ y de"Inversión Social (PRIS)”. ${ }^{12}$ Esta línea había retomado una familia de palabras que anudaba políticas sociales con ciertas prácticas: perfil socio-productivo, autogestión, cooperativismo, universalización, integralidad, inclusión, economía social y solidaria, capital social, participación. Esta terminología no era nueva, sino que se encontraba en los documentos del Banco Mundial (Massetti, 2011).

En este marco, deben entenderse las características del PRIST. La primeraalude al tipo de formación de las cooperativas: estas fueran creadas por los gobiernos locales (municipios) en vez del modo clásico de vínculo horizontal y comunitario de sus integrantes (Natalucci, et. al., 2013). ${ }^{13} \mathrm{La}$ segunda es que las actividades de los cooperativistas se orientaban a la realización de obras de infraestructura local y/o saneamiento quecontribuían al mejoramiento de las condiciones de vida de susterritorios. La tercera remite a su carácter focalizado hacia un sector con restricciones en el acceso, de su selectividad respectode los beneficiarios, de su integralidad, y acceso al "monotributo social", ${ }^{14}$ obra social y vacaciones (MDSN, 2010).$^{15}$ La cuarta característica remite a la contraprestación de cada cooperativista, donde cada uno debía cumplir con 40 horas semanales de trabajo y realizar un curso de perfeccionamiento de su oficio original o de terminalidad de los ciclos educativos, asistencia y promoción de la salud y de la familia, contable y jurídica. Resumiendo, había un esfuerzo gubernamental por reforzar la práctica cooperativa y las capacidades subjetivas de los beneficiarios, pero bajo una lógica regida por la focalización, la selectividad y la contraprestación.

La última característica alude a la relación con las organizaciones. Si bien desde la asunción del kirchnerismo en 2003, las organizaciones habían adquirido un importante rol en gestión de la política social (Gómez y Massetti, 2009; Gradin, 2015; Perelmiter, 2012), el PRIST marcó un punto de inflexión ya que retomaba la experiencia de las organizaciones en otros programas autogestivos. Sin embargo, las primeras disputas no se hicieron esperar. La primera ocurrió en el momento de formación de cooperativas, la discusión era si estas tareas deberían recaer sobre los gobiernos municipales o las organizaciones. Hasta entonces, ambos habían compartido la gestión de programas sociales en los territorios; pero el gobierno nacional en su afán por recentralizar la política social decidió que los gobiernos municipales se 
ocuparan de su implementación. El cuestionamiento de las organizaciones remitía a que los municipios desalentaban el carácter organizativo y horizontal singularde las cooperativas. Para saldar este conflicto, el gobierno nacional abrió una segunda etapa de implementación, donde las organizaciones tenían un “cupo” de cooperativas. Esta resolución no fue igualitaria para todas las organizaciones, variaba según su nivel de acuerdo con el gobierno nacional (Natalucci, 2012b).La segunda disputa tuvo lugar durante la implementación del PRIST y remitía a problemas ejecutivos relacionados con la recepción de los materiales para la realización de las obras y el pago a los cooperativistas.

Resumiendo, la principal críticahacia el PRIST por parte de especialistas y de las organizaciones involucradas es que se haya implementado por intermedio de los gobiernos locales. Vale recordar que acerca de la orientación individualizadora o colectivizadora del PRIST fue decisivo si su gestión recayó sobre los gobiernos locales o sobre las organizaciones. ${ }^{16}$ Aunque la resolución del conflicto “desde arriba” apelaba a reconstruir la institucionalidad estatal, chocaba con prácticas enraizadas en las organizacionesque, creadas al calor de la crisis de 2001, estaban acostumbradas a gestionar la política social en relación directa con el ámbito nacional. Durante esa crisis, por un lado, las organizaciones se habían conformado en instancias intermedias imprescindibles para la gestión de la política social, por conocimiento del territorio, por el grado de organización interna y por contar con militantes. Por otro, habían adquirido expertise en el sentido de una apropiación singular de ese discurso neoliberal que paradójicamente les permitió consolidarse como sujeto político. Finalmente, las organizaciones negociaban en conjunto con los gobiernos; por lo que la negociación en particular deteriorabasus lazos de solidaridad. Una crítica complementaria que realizaban las organizaciones es que, en el momento de la implementación, el espíritu del PRIST se había desvirtuado. Aunque su objetivo original había sido subsidiar la creación de empleo frente a la crisis internacional de 2009, para la percepción de las organizaciones había funcionado como un "plan social disfrazado” al no facilitar el desarrollo de las cooperativas. ${ }^{17}$

Aún con estos cuestionamientos, el PRISTfue decisivo en un desplazamiento que ya tenía tiempo gestándose:el de la identidad piquetera o trabajador desocupado. Hasta entonces esta identificación había marcado las trayectorias de las organizaciones y aunque estas intentaran reposicionarse como territoriales o “populares”; el PRIST se constituyó como una posibilidad para constituirse como trabajadores de la economía popular. Este desplazamiento tuvo una significativa consecuencia en el plano organizativo ya que propició la conformación de la Confederación de Trabajadores de la Economía Popular (CTEP).

\section{Agencias sociales y experiencias organizativas}

El 2 de agosto de 2011 en el Teatro Verdi de la ciudad de Buenos Aires se realizó un plenario de organizacionesque agrupaban a diferentes 
tipos de trabajadores: el ME, la Cooperativa textil La Alameda, el Movimiento Nacional de Empresas Recuperadas por los Trabajadores (MNER) y el Movimiento de Trabajadores Excluidos (MTE). Allí resolvieron "la construcción de una organización unitaria, confederal, amplia y fuerte”, de carácter "social, independiente de todos los partidos políticos y representativa de los trabajadores de la economía popular y sus familias”, que solicitara “a la Confederación General del Trabajo (CGT) su admisión dentro de su estructura orgánica” (Declaración Teatro Verdi, mayo de 2011). Allí fue fundada la CTEP, una “organización sindical multitendencia y multi-rama, de cuño reciente y carácterreivindicativo, en la que convergen agrupamientos con inscripciones político-ideológicasdiversas” (Bruno, Coelho y Palumbo, 2017, p. 92). ${ }^{18}$

La CTEP tiene una doble lógica de organización. Por un lado, las ramas de actividad entendidas como la "actividad económica principal de la unidad productiva” (Pérsico y Grabois, 2014a, p. 41), cartoneros, indumentaria, motoqueros, vendedores de la vía pública, programas sociales, artesanos, feriantes y pequeños agricultores. Por otro lado, una estructura de decisión política distribuida en un secretariado nacional, responsables de cada rama y delegados de base. ${ }^{19}$ Esta doble lógica evidencia la tensión con el pasado de las organizaciones, donde muchas venían de una experiencia piquetera o asociada a la figura de trabajador desocupado con una lógica de movimiento social anclado en un territorio. Sin embargo, la apuesta por la CTEP implicaba reivindicar la lógica sindical, reforzando el desplazamiento de desocupado a trabajador, aunque fuera informal.

\section{La reconfiguración en las formas de identificación}

Pérsico y Grabois, dirigentes del ME y el MTE respectivamente, publicaron una serie de materialesinternos titulados "Nuestra Realidad.Cuadernos de formación para trabajadores, militantes, delegados y dirigentes de organizaciones populares”, donde se encuentran los principales fundamentos de la organización. La CTEP ha partido de la caracterización sobrela fragmentación de la clase trabajadora, evidenciada en el hecho que por lo menos dos generaciones "no conocen la vidade la fábrica, el taller, nunca gozaron de un sueldodigno, vacaciones, aguinaldo, obra social ni un sindicato” (Ibid, 2014a, p. 2 y 3).Esta fragmentación era atribuida a una economía que funcionaba a "tres velocidades: en avión, en tren y en chancletas” (2014a: 25), a la que le correspondía un fragmento de la clase: “el agua, la leche y la crema (2014a: 28). ${ }^{20}$

Estas caracterizaciones circunscribían el objeto de la disputa para la CTEP: quién puede considerarse trabajador y cómo nombrar a aquellos que no gozan de la seguridad social, tienen ingresos dispares oun empleador visible. Pérsico y Grabois (2014a) se preguntan por los trabajadores que integraban la CTEP: informales, precarios, productivos y sobre todo necesarios para el capitalismo pero "descartados” para la integración social. La denominación de trabajadores de la economía popular intentaba sintetizar esta posición. 
¿Por qué trabajadores y no desocupados? Esta diferencia, por un lado, apelaba a poner en discusión que el único trabajo legítimo fuera el asalariado (Grabois, 2017). Este figuraba dentro de su horizonte de expectativas, sin embargo,en el marco de un capitalismo que no genera pleno empleo había que buscar un nombre para aquellos que se "habían inventado su propio trabajo”. Por otro lado, era una estrategia de reconocimiento positivo, no eran inempleables o desocupados, sino que tenían un trabajo de características diferentes. Por último, les permitía repensar las formas de representación y de articulación interorganizacional; específicamente tender lazos con la CGT. Esto último permitiría según la perspectiva de la organización de construir una articulación política con los trabajadores formales que permitiera superar la fragmentación de la clase.

¿Por qué economía popular y no economía social? ${ }^{21}$ Para la organización, la economía se dividía según los propietarios de sus medios de producción: los sectores populares en el caso de la economía popular y de los capitalistas en la de mercado.Lo popular radicaba entonces en la pertenencia de los trabajadores a un segmento socioeconómico. Para la CTEP, la economía popular es la economía de los excluidos en tanto se conforma por "las actividades que surgieron como consecuencia de la incapacidad del mercado capitalista para ofrecernos a todos un trabajo digno y bien remunerado como obreros en una fábrica o trabajadores de una empresa (Pérsico y Grabois, 2014a,p. 35).

\section{La institucionalización conflictiva}

Siguiendo a Bruno, Coelho y Palumbo (2017), la CTEP podría caracterizarse como una innovación organizacional en el sentido de una forma organizativa donde se cruzan procesos de cambio organizacional, problemáticas vinculadas a la supervivencia y nuevos repertorios de acción. De acuerdo con Dinerstein, Contartese y Deledicque (2010), esos procesos de innovación organizativos se relacionan a su vez con otros dos procesos: la creación de "políticas de bienestar desde abajo" y la "institucionalización conflictiva”.Mientras el primero alude a la dimensión productiva y cooperativa de los proyectos que se orientan a "cuestiones claves del bienestar público general como tendido de redes de agua potable o construcción de viviendas, desmalezamiento, reciclaje o defensa del medio ambiente, reemplazando en muchos casos al municipio o gobierno local” (Ibid, 2017, p. 97), el segundo remite a la relación con el Estado.

Respecto de este punto, no todas las organizaciones que se integraron a la CTEP eran afines al gobierno kirchnerista, ni todas habían participado específicamente del PRIST; incluso para muchas de aquellas la respuesta que el kirchnerismo había dado a la crisis de 2009 era insuficiente. Su punto de identificación se encontraba más bien en la experiencia originaria vinculada a sus condiciones de trabajo y de reproducción de la vida cotidiana, pero también a un imaginario reactivado por el kirchnerismo que asociaba movilidad social ascendente e intervención del Estado, junto con la mencionada recreación de la gramática movimentista. Asimismo, el proce- 
so de revitalización sindical por el que los sindicatos habían recuperado poder corporativo y político había convertido a lo "sindical” en una forma organizativa y representativa atractiva. En pocas palabras, estos sectores habían mejorado sus condiciones de vida respecto de 2002, pero ese horizonte que el kirchnerismo promovía seguía estando lo suficientemente alejado.

Asimismo, ese imaginario y lógica de construcción políticaalentada por el gobierno encontraba un fuerte obstáculo: el Estado ya no era el bienestarista, sino uno posneoliberal con diferentes condiciones de posibilidad y modos de intervenir en la economía y los territorios. Más allá de la manifiesta voluntad política de proclamar "más Estado y menos mercado", había condiciones estructurales que no podían ignorarse, entre ellas la lógica de mercantilización que atravesaba todos los ámbitos sociales. Esto generó una situación conflictiva entre los imaginarios reactivados, las expectativas organizacionales y las condiciones realmente posibles para su concreción. En estos desfasajes la CTEP encontró un lugar vacante de representación.

Estos desacuerdos internos fueron decisivos para que,desde su creación hasta diciembre de 2015, la CTEP optara por privilegiar su consolidación e institucionalización. Esta última erapensada en un doble sentido. Por un lado, como la diferenciación interna de roles y jerarquías como de identificación de las instancias de toma de decisiones. Por otro, en un sentido pragmático,unproceso de estabilización de regularidades y pautas comunes que se juegan en lugares de la política estatales y no estatales y que afectan no sólo a los integrantes de la organización, sino al universo de representación. En este marco, la CTEPdesplegódos estrategias: una de crecimiento de las ramas y de extensión federal y otra dereconocimiento estatal con la consecuente obtención de una personería gremial, como la que tienen las organizaciones sindicales según la normativa vigente. Esto último era controversial para dos actores importantes involucrados. Para el gobierno porque suponía darle un estatuto y perdurabilidad a un actor que no necesariamente era afín en términos políticos oprogramáticos. Para los sindicatos porque discrepaban con la figura de trabajador de la economía popular que socavaba la legitimidad del trabajador asalariado y podía competir por la representación de la clase trabajadora. En este contexto, en su último día de mandato, Fernández de Kirchner firmó la resolución de otorgamiento de unapersonería social (en vez de gremial como pretendían las organizaciones); sin embargo, como no fue publicada en el boletín oficial no revestía de legalidad.

Este fueel primer pedido que la CTEP le formuló al gobierno de Cambiemos. En enero de 2016, el ministro de Trabajo Jorge Triaca firmó la resolución 32/16 por la que se creó el "régimen de agremiación complementario, ampliatorio y compatible con el modelo sindical vigente” (Grabois, 2017, p. 13).Pese a este avance en su institucionalización, la CTEP modificó radicalmente su estrategia. Brevemente, la asunción de Mauricio Macri significó un nuevo giro neoliberal por la adopción de una política económica ortodoxa, la concepción de un Estado cuya intervención sobre la sociedad civil 
debe estar tercearizada vía ONG y la redefinición de la política socialhacia la asistencia. Este nuevo contexto aparejó una creciente pauperización de las condiciones de vida de los sectores populares; según datos del Observatorio de la Deuda Social de la Universidad Católica Argentina, la pobreza en 2015 alcanzaba al 29\% de la población y ya en el primer trimestre de 2016 ascendió al 34,5\%. Es menester recordar que, si bien la CTEP no sólo incluye a beneficiarios del PRIST, la redefinición de la política social, el vaciamiento del MDS y la crisis económica implicó la progresiva desaparición de las changas, el modo en que los argentinos le llaman a los trabajos provisorios que les permiten vivir día a día.

Esta situación fue decisiva para que la CTEP cambiara su estrategia y paradójicamente en un momento de agudización de la crisis encontrara condiciones para ampliar su institucionalización.Coincidentemente, se produjo un hecho clave a partir de la aparición de un aliado inesperado.En marzo de 2013 había sido ungido Papa de la Iglesia Católica el cardenal argentino, Jorge Bergoglio, quien tenía una estrecha y larga relación con dirigentes de la CTEP, como Grabois (MTE) y Gustavo Vera (Cooperativa La Alameda). Desde su asunción, el Papa habíaproclamado la consigna "Techo, Tierra y Trabajo” e impulsado el Encuentro Mundial de Movimientos Populares (Roma 2014 y 2016; Santa Cruz de la Sierra, 2015), en los cuales ha participado la organización. Esta consigna, aunque no fuera nueva, le permitió a la organización contar con un marco simbólico que le permitió referenciarse más allá de las adscripciones partidarias y posicionarse como un actor clave en un problema público que remitía a derechos sociales básicos.

En este nuevo contexto, desde 2016 la CTEP, Barrios de Pie y la Corriente Clasista y Combativa impulsaron la Campaña "Ley de Emergencia Social Ya! + Dignidad + Más trabajo”. Aquella tenía una estrategia bifronte. Por un lado, la representación parlamentaria del Movimiento Evita presentóel proyecto "Ley de emergencia social y de las organizaciones de la economía popular”. Entre sus puntos centrales estaban: la declaración de la emergencia social;la institucionalización de la economía popular; la creación del Registro de Organizaciones Sociales de la Economía Popular y Empresas Autogestionadas, de unsistema de protección social destinado a trabajadores desocupados, precarios o informales y de un millón de puestos de trabajo; la implementación de un Salario Social Complementario (SSC), equivalente al 50\% del salario mínimo, vital y móvil y un aumento de la AUH.Por otro lado, las organizaciones lanzaron un plan de lucha, que incluía ollas populares y movilizaciones callejeras. El 18 de noviembre organizaron una concentración multitudinaria frente al Congreso de la Nación junto con la CGT para reclamar la sanción de la ley. Esta campaña marcó un punto de inflexión para la CTEP ya que le permitió tomar una alta visibilidad en el espacio público, profundizar sus relaciones con la CGT y reforzar su carácter de representante de una fracción de la clase trabajadora.

En diciembre de ese año, el proyecto se convirtió en la ley № 27345.En el texto definitivo se eliminaron los artículos referidos a la creación de puestos de trabajo y el aumento en la AUH mientras se resaltaron cuestiones 
vinculadas a la promoción de los derechos de los trabajadores. Aunque a priori podría pensarse como un cambio positivo, lo cierto es que demostró la intención del gobierno de reconvertir la política social. Esta primera evidencia quedó clara por dos hechos posteriores que, al mismo tiempo,marcaron un límite en la institucionalización de la CTEP. Por un lado, en mayo de 2017 empezó a implementarse el "Plan Empalme” para el PRIST, orientado a la preparación, capacitación y orientación de la población beneficiada hacia el mercado privado. Este corrimiento no sólo desdibujaba el perfil productivo, sino que realzaba únicamente la cuestión de la empleabilidad de esos sectores. El segundo se produjo en junio cuando el MTEySS no aceptó que la organización participara de las reuniones del Consejo del Salario, el órgano tripartito donde se resuelve el aumento anual del salario mínimo. La posición de la CTEP era que si sus representados cobraban el SSC y que este representaba el 50\% del salario mínimo tenían derecho a participar en su resolución. La imposibilidad de participar de esta instancia mostraba la fragilidad de la personería social conseguida.

Para finalizar, es importante destacar que la activación del discurso neoliberal y sus prácticas trastocaron ese proceso de institucionalización conflictiva en un doble sentido. Por un lado, pese a la intención de convertirse en un sindicato, la tensión entre lógica de movimiento social y sindical pareciera haberse inclinado hacia el primero. Por otro lado, respecto de su relación con el Estado pareciera que el reconocimiento otorgado vía personería social fue suficiente para asentar la representación sobre el universo de los trabajadores informales, pero no para conseguir recursos y reactivación de políticas beneficiosas para el sector.

\section{Reflexiones finales}

Recapitulando, el objetivo de este artículo ha sido analizar un caso de "neoliberalismo realmente existente", en particular una política social específica a partir de la cual indagar sobre condiciones estructurales y agenciales. Como se mencionó, adherir a la premisa que el neoliberalismo es constitutivo y a la vez constringente pero no determinante implica comprender cómo genera un campo de acción posible donde los actores sociales mantienen su capacidad de agencia y transformación. Este ejercicio analítico tomando el caso del PRIST se justificaen tanto condensa una serie de tensiones: cambios societales, tipo de intervención estatal y la resignificación de la agencia.El análisis de una política social no implica solamente considerar su normativa y los discursos gubernamentales, sino también indagar en qué hacen los actores sociales con ella.

La hipótesis que ordenó la exposición reunía dos aspectos, su dimensión normativa y la agencia de los actores. Como se expuso, el PRIST tuvo una lógica neoliberal que combinaba criterios de focalización y selectividad con un perfil socio-productivo pero al mismo tiempo instituyó un nuevo campo de acción. De esta manera, se constituyó en una oportunidad para los trabajadores informales por lo menos en dos planos, por un lado, 
su reconocimiento como trabajadores y, por otro,la emergencia de una nueva representación para ellos. En este sentido, aunque el neoliberalismo como discurso atraviese los diferentes ámbitos e impregne de ciertos sentidos a la lógica estatal, los actores sociales hicieron uso de su capacidad propositiva para leerlo como una oportunidad. Al respecto hay que señalar dos cuestiones principales,la primera remite a repensar la gravitación de las dimensiones estructurales. Es cierto que en el contexto posneoliberal, los gobiernos kirchneristas tuvieron un discurso a favor de más Estado y menos mercado que fue decisivo para la redefinición de la política social, la intervención del Estado sobre la sociedad civil y de la concepción sobre la política económica. Sin embargo, es innegable que el neoliberalismo como discurso en el sentido que le atribuye Springer no está al alcance de la voluntad de los dirigentes políticos. Aquel ha delineado por décadas estilos gubernamentales yformas de subjetivación, que no se suspenden repentinamente por la decisión política de actores particulares.

El neoliberalismo más bien atraviesa diferentes ámbitos sociales, tanto a nivel nacional como internacional, en los discursos como en las agencias. Ahora bien, esta concepción no implica desconocer la capacidad de agencia de los actores a partir de la cual pueden tener una actitud propositiva frente a las cuestiones estructurales. En este punto, la constitución de la CTEP muestra que los actores tienen ideas, pueden pensar estrategias, construir posiciones políticas que les permitan desafiar el lugar que se les atribuye. Entre la lógica de mercantilización, la proclama de “más Estado y menos mercado” y los imaginarios y expectativas mencionados se generó un campo potencial para la CTEP como representante de ciertos sectores.

Estas palabras pueden parecer una obviedad sociológica, sin embargo, son recurrentes las intervenciones académicas, políticas, técnicas o periodísticas donde la dimensión agencial está ausente y desligada de aspectos estructurales. Por el contrario, como intentó demostrarse en este artículo, las nuevas experiencias organizativas demuestran que los procesos de ampliación de ciudadanía, aunque tuvieron una retracción a propósito del neoliberalismo, por la agencia de los actores sociales y políticosencontraron nuevas formas de expresarse. Tienen mucho para decirnos acerca de cómo se anudan los vínculos entre neoliberalismo, política y ciudadanía, por esto ameritan estudios particulares.

\section{Agradecimientos}

Este artículo presenta resultados de la investigación “¿Fin del giro a la izquierda en Argentina? Política y Movilización en el último gobierno kirchnerista (2011-2015)" el marco de mi trabajo como Investigadora Adjunta del CONICET (Argentina). Un avance preliminar de este artículo se encuentra en prensa: "Entre idas y vueltas. Contrapuntos sobre la intervención territorial y la construcción de estatalidades (Argentina, 2009-2015)” en Vommaro Gabriel (Ed.) Desigual. Conflictos y contradicciones del Estado, los derechos y la democracia en Argentina, Buenos Aires, UNGS-CLACSO. 


\section{Notas}

${ }^{1}$ En su libro "Breve historia del neoliberalismo", Harvey sostiene que el neoliberalismo es una teoría de prácticas político-económicas donde la mejor manera de promover el bienestar del ser humano consiste en no "restringir el libre desarrollo de las capacidades y de las libertades empresariales del individuo dentro de un marco institucional caracterizado por derechos de propiedad privada fuertes, mercados libres y libertad de comercio. El papel del Estado es crear y preservar el marco institucional apropiado para el desarrollo de estas prácticas” (2015, p. 6).

${ }^{2}$ Siguiendo a de Lagasnerie, el neoliberalismo se sustenta sobre la utopía de una sociedad donde impere la competencia, donde "la única forma de organización social válida es el mercado" (2012, p. 35). Este imperativo marca la diferencia entre "el liberalismo clásico (Smith, Ricardo, Say) y el neoliberalismo” (Ibid). Sintéticamente mientras el liberalismo proponía la restricción de "la intervención del Estado, de fijarle una serie de límites para despegar un espacio 'libre' donde los mecanismos de mercado pudieran actuar sin coacciones externas” (Ibid, p. 36), el neoliberalismo propone difundir "el mercado por todas partes" (Ibid. Cursivas en el original). Es decir, si el liberalismo aceptaba la coexistencia de dos racionalidades, una económica para el mercado y otra política para el Estado, el neoliberalismo acepta sólo la económica para todas las esferas de la vida.

${ }^{3}$ Para la escritura de este artículo se utilizaron datos elaborados a partir de un extenso trabajo de campo que implicó el seguimiento de las actividades y entrevistas en profundidad a dirigentes de la CTEP y a los agentes del programa y la reconstrucción de los discursos a partir de materiales producidos por los actores involucrados.

${ }^{4}$ La bibliografía sobre la relación entre los movimientos sociales y el kirchnerismo es abundante, entre ellos Gómez y Massetti (2009); Gradin (2015); Perelmiter (2012); Pérez y Natalucci (2012); Natalucci (2015); Retamozo (2011), Rocca Rivarola (2013) y Schuttenberg (2014).

${ }^{5}$ Por medio del decreto 1506/04, el gobierno nacional extendió hasta el 31 de diciembre de 2005 la Ley de Emergencia Ocupacional Nacional ( $\left.\mathrm{N}^{\circ} 25.561\right)$ junto con la prórroga y reformulación del Programa Jefes de Hogar (Decreto 165/2002).

${ }^{6}$ Los planes Nacional de Desarrollo Local y Economía Social (“Manos a la Obra”), Nacional de Seguridad Alimentaria ("El hambre es más urgente”) y Familias quedaron bajo la órbita del Ministerio de Desarrollo Social (MDS) mientras que el Plan Integral de Promoción del Empleo ("Más y mejor Trabajo) en el de Trabajo, Empleo y Seguridad Social (MTEySS).

${ }^{7}$ Vale aclarar al lector que estas estadísticas son aproximadas debido la falta de información oficial. En general, ese 30\% de la población es acordado por diversos autores: Basualdo E. (2008), Guimenez y Hopp (2011) y la UCA (2010).

${ }^{8}$ Estas declaraciones tuvieron lugar en el acto realizado el 11 de marzo de 2010 en el club Ferrocarril Oeste de la Ciudad de Buenos Aires, con la consigna "En defensa del consumo popular y el salario". En Natalucci (2012b) puede encontrarse información ampliada respecto del posicionamiento de las organizaciones frente a la crisis de 2009 
y la acción del gobierno para compensar las desigualdades sociales. Para ampliar sobre el ME véase Gómez y Massetti (2009); Natalucci (2012a) y Schuttenberg (2014).

${ }^{9}$ En octubre de 2009 se implementó la Asignación Universal por Hijo para Protección Social (AUH), un clásico programa de Transferencia Condicionada que implica una retribución monetaria directa y mensual a madres sin trabajo con hijos a cargo. Este conjunto de programas se completó con la implementación de dos programas más: en 2009 el programa de Inclusión Provisional destinado a personas en edad de jubilarse pero sin los aportes requeridos y en 2013 el "Ellas Hacen”.Véase García Delgado (2011), Massetti (2011) y Arcidiácono, Kalpschtrej y Bermúdez (2014).

${ }^{10}$ Página/12, “CFK: El trabajo es el mejor antídoto contra la pobreza”, 14-08-2009, Versión electrónica.

${ }^{11}$ Este programa fue implementado en agosto de 2004, se trataba de la entrega de subsidios a cooperativas. En 2010, fue incorporado a la estructura del PRIST (Arcidiácono, Kalpschtrej y Bermúdez, 2014).El mayor obstáculo de las cooperativas se relacionaba con la etapa de comercialización, por lo que su supervivencia dependíade las compras del Estado.

12 Este programa fue impulsado por Emilio Pérsicoen el primer semestre de 2009 mientras se desempeñaba como Subsecretario de Comercialización de la Economía Social en el MDS.Su formulación retomaba el obstáculo de la comercialización, por eso las cooperativas se desempeñaban en actividades de servicios y de obra pública (Natalucci, 2012b).

${ }^{13}$ Cada cooperativa se integraba por 50 o 60 personas y debía inscribirse en el Instituto Nacional de Asociativismo y Economía Social (INAES); estaba compuesta por trabajadores y capataces y orientadores, entre los que se establecía una relación jerárquica, ya que muchas veces estos últimos actuaban como vínculos entre el gobierno local y las cooperativas. Estas diferencias también se hicieron visibles en los ingresos, alrededor de mil pesos de diferencia. Para ser beneficiario era necesario pertenecer a hogares en situación de vulnerabilidad socio-económica, no tener ingresos familiares provenientes de programas sociales, estar registrado como empleado en actividad o recibir seguro de desempleo y estar domiciliado en las localidades prioritarias para la implementación del programa.Respecto de su cobertura, Arcidiácono, Kalpschtrej y Bermúdez (2014) afirman que para octubre de 2012 el programasuperaba los 200 mil cooperativistas.

${ }^{14}$ El monotributo social implica la inscripción de trabajadores informales en la Administración Federal de Ingresos Públicos (AFIP).

${ }^{15}$ El programa tuvo dos etapas de implementación: 2009-2012 y 2012-2015, donde tuvo dos cambios: 1) reducción de la cantidad de cooperativistas, de 50 o 60 pasó a 30 personas y 2) la incorporación de pagos por presentismo y productividad.

${ }^{16}$ Por una cuestión de espacio no es posible explayarme sobre este aspecto. Véase Natalucci et. al, (2013).

${ }^{17}$ Información obtenida de dirigentes del ME y MTE en entrevistas realizadas por la autora en la ciudad de Buenos Aires, noviembre de 2016. 
${ }^{18}$ El nombre jurídico es Asociación Civil de los Trabajadores de la EconomíaPopular (ACTEP), está inscripta en el Registro de Organizaciones Sociales de la EconomíaPopular y Empresas Autogestionadas, creado por el MTEEySS.

${ }^{19}$ El Secretariado Nacional está integrado por el secretario general, un coordinador de Unidades Productivas, un secretario de vivienda, salud, deporte, prensa, educación y relaciones institucionales (Pérsico y Grabois, 2014b).

${ }^{20}$ Esta última idea estaba relacionada con el acceso al consumo que cada sector podía hacer: "los hijos de algunos trabajadores pueden tomar un yogurt cremoso, otros la leche chocolatada y los menos favorecidos, sólo agua o mate cocido" (Pérsico y Grabois, 2014a, p. 30).

${ }^{21}$ Por una cuestión de espacio no podré explayarme en la diferencia entre economía social y popular, véase Natalucci (en prensa). 


\section{Bibliografía}

Alvarez, S. et. al.(Ed.) (2017). Beyond civil society. Activism, Participation, and Protest in Latin America", Durham, UK: Duke University Press Durham.

Arcidiácono, P., Kalpschtrej, K. y Bermúdez, Á. (2014). ¿Transferencias de ingresos, cooperativismo o trabajo asalariado? El Programa Argentina Trabaja. Revista Trabajo \& Sociedad, 22, 341-356. Recuperado de: http://www.scielo.org.ar/scielo.php?script=sci_arttext\&pid= S1514-68712014000100019.

Arias, A. (2013). Lo territorial en el territorio de la Argentina. Connotaciones históricas, políticas y culturales de lo social de los territorios. RevistaMargen, (71), 1-7. Recuperado de: https://www.margen.org/ suscri/margen71/arias.pdf.

Brenner, N, Peck, J. y Theodore, N. (2010). After Neoliberalization? Revista Globalizations, 7 (3), 327-345. doi: 10.1080/14747731003669669.

Basualdo, E. (2008). La distribución del ingreso en la Argentina y sus condicionantes estructurales. En CELS Derechos humanos en Argentina. Informe 2008 (307-326). Buenos Aires, Argentina: Siglo XXI Editores.

Castel, R., et. al. (2013). Individuación, Precariedad, Inseguridad. ¿Desinstitucionalización del presente? Buenos Aires, Argentina: Paidós.

Bruno, D., Coelho, R. y Palumbo, M. M. (2017). Innovación organizacional e institucionalización conflictiva de las organizaciones de la economía popular. El caso de la Confederación de Trabajadores de la Economía Popular (CTEP). Argumentos. Revista de Crítica Social, (19). Recuperado de: http://publicaciones.sociales.uba.ar/index.php/argumentos/article/viewFile/2551/2120.

Collier, R. B. y Collier, D. (1991). Shaping the Political Arena: Critical Junctures, the Labor Movement, and Regime Dynamics in Latin America. Princeton, New Jersey: Princeton University Press.

de Lagasnerie, G. (2012). La última lección de Michel Foucault: sobre el neoliberalismo, la teoría y la política. Buenos Aires, Argentina: Fondo de Cultura Económica.

Dinerstein, A., Contartese, D y Deledicque, M. (2010). La ruta de los piqueteros: luchas y legados. Buenos Aires, Argentina: Capital Intelectual.

Foucault, M. (2004). Nacimiento de la biopolítica, Buenos Aires, Argentina: Fondo de Cultura Económica. 
Gago, V. (2014). La razón neoliberal, Buenos Aires, Argentina: Tinta Limón Ediciones.

García Delgado, D. (2011). La cuestión social en una estrategia a mediano plazo. En D. García Delgado y M. Peirano (Comp.) El modelo de Desarrollo con Inclusión Social: la estrategia a mediano plazo (5576). Buenos Aires, Argentina: CICCUS.

Gómez, M. y Massetti, A. (2009), Los movimientos sociales dicen. Conversaciones con dirigentes piqueteros sobre el proyecto nacional y latinoamericano, Buenos Aires, Argentina: Nueva Trilce.

Grabois, J. (2017). Personería social: perspectivas en torno al nuevo régimen de agremiación para los trabajadores de la economía popular. Buenos Aires, Argentina: Universidad de Derecho.

Gradin, A. (2015).La participación política de las organizaciones de desocupados en el Estado nacional durante el periodo 2003 - 2009. La experiencia del Movimiento Barrios de Pie: sus límites y potencialidades (Tesis de Doctorado). Universidad de Buenos Aires, Buenos Aires, Argentina.

Grugel J. y Riggiorizzi, P. (2012). Post-neoliberalism in Latin America: Rebuilding and Reclaiming the State after Crisis. Development and Change, 43 (1), 1-21. Doi: 10.1111/j.1467-7660.2011.01746.x.

Guimenez, S. y Hopp, M. (Mayo de 2011). Programa Ingreso Social con Trabajo “Argentina Trabaja”: una mirada reflexiva desde el corazón de su implementación. IV Encuentro Internacional de Trabajo Social, Buenos Aires, Argentina.

Harvey, D. (2015). Breve historia del neoliberalismo. Madrid, España: Akal.

Kessler, G. (2014). Controversias sobre la desigualdad. Argentina, 20032013. Buenos Aires, Argentina: Fondo de Cultura Económica

Lemke, T. (Septiembre de 2000) Foucault, Governmentality, and Critique. En Rethinking Marxism Conference, Amherst, Estados Unidos.

Levitsky, S. y Roberts, K. (Eds.) (2011). The Resurgence of the Latin American Left. Baltimore, Estados Unidos: Johns Hopkins University Press.

Lo Vuolo R. (2010).El programa “Argentina Trabaja” y el modo estático de regulación de la cuestión social en el país. Buenos Aires, Argentina: CIEPP. 
Massetti, A. (2011). Las tres transformaciones de la política pública asistencial y su relación con las organizaciones socio-políticas (20032009). Revista Entramados y Perspectivas, 1 (1), 9-36. Recuperado de: http://publicaciones.sociales.uba.ar/index.php/entramados yperspectivas/article/viewFile/18/18.

Ministerio de Desarrollo Social de la Nación (MDS) (2009). Informe Proceso de aprobación para la incorporación al Programa de Ingreso Social con Trabajo. Recuperado de: https://www.desarrollosocial. gob.ar/wp-content/uploads/2015/07/3.-Proceso-de-aprobacion-parala-incorporacion.pdf.

Ministerio de Desarrollo Social de la Nación (MDS) (2010). Distribuidor Programa de Ingreso Social con Trabajo: Provincias Argentinas. Recuperado de: https://www.desarrollosocial.gob.ar/wp-content/ uploads/2015/07/4.-Distribuidor-Ingreso-Social-con-Trabajo.pdf.

Ministerio de Desarrollo Social de la Nación (MDS) (2014), Programa Ingreso Social con Trabajo. Síntesis de resultados e impactos después de cinco años de sus primeros pasos. Recuperado de: https:// www.desarrollosocial.gob.ar/wp-content/uploads/2015/11/INFORME-DE-INDICADORES-DE-RESULTADOS.pdf.

Morresi, S. (2011). La larga construcción de la hegemonía neoliberal. En G. Pérez, et. al. (Ed.) Todo aquel fulgor. La política argentina después del neoliberalismo (67-78), Buenos Aires, Argentina: Nueva Trilce.

Natalucci, A. (2012a). Los movimentistas. Expectativas y desafíos del Movimiento Evita en el espacio kirchnerista (2003- 2010). G. Pérez y A. Natalucci Vamos las bandas. Organizaciones y militancia kirchnerista (27-56). Buenos Aires, Argentina: Nueva Trilce.

Natalucci, A. (2012b). Políticas sociales y disputas territoriales. El caso del programa Argentina Trabaja. Revista de Perspectivas de Políticas Públicas, (3), 126-147. doi: http://dx.doi.org/10.18294/ rppp.2012.614.

Natalucci, A. (2015). Mobilização social e mudanças políticas: revisitando o conceito de gramáticas de ação política. Plural, 22 (1), 83-106. Recuperado de: http://www.revistas.usp.br/plural/article/view/ 102215.

Natalucci, A. et. al. (2013). Territorios disputados. Movilización política y procesos de institucionalización en niveles locales de gobierno (Argentina, 2003-2011). Revista Mexicana de Análisis Político y Administración Pública, 2 (2), 139-159. Recuperado de: http:// www.remap.ugto.mx/index.php/remap/article/view/59. 
OIT. (2005). Recomendación 195. Sobre?el desarrollo de los recursos humanos: educación, formación?y aprendizaje permanente. Recuperado de: https://www.oitcinterfor.org/sites/default/files/edit/docref/ rec195.pdf.

Papalini, V. y Natalucci, A. (2005). Poder y empoderamiento. De las luchas políticas a la vía individual. Revista Tramas, 24, 205-228.

Perelmiter, L. (2012). Fronteras inestables y eficaces. El ingreso de organizaciones de desocupados a la burocracia asistencial del Estado. Argentina (2003-2008).Revista Estudios Sociológicos, 30 (89), 431458. Recuperado de: http://www.jstor.org/stable/41938091.

Pérez, G. (2011). Neoliberalismo y política. En G. Pérez, et. al. (Ed.) Todo aquel fulgor. La política argentina después del neoliberalismo (1118), Buenos Aires, Argentina: Nueva Trilce.

Pérez, G. y Natalucci, A. (2012). Vamos las bandas. Organizaciones y militancia kirchnerista. Buenos Aires, Argentina: Nueva Trilce.

Scarfó, G., Hopp, M. y Highton C. (2009). Reflexiones en torno al concepto de inempleabilidad: consideraciones para pensar la política social. RevistaPlaza Pública, (2) 2, 8-20. Recuperado de: https:// revistaplazapublica.files.wordpress.com/2014/06/scarfo-y-otras.pdf.

Pérsico, E. y Grabois, J. (2014a). Nuestra Realidad.Cuadernos de formación para trabajadores, militantes, delegados y dirigentes de organizaciones populares, (1), Buenos Aires, Argentina: Punto Sur.

Pérsico Emilio y Grabois Juan (2014b), Nuestra Realidad.Cuadernos de formación para trabajadores,militantes, delegados y dirigentes de organizaciones populares, (2), Buenos Aires, Argentina: Punto Sur.

Retamozo, M. (2011). Movimientos sociales, política y hegemonía en Argentina. Polis. Revista Latinoamericana, 10(28), 243-279. Recuperado de: http://www.scielo.cl/scielo.php?pid=S0718-656820 11000100014\&script=sci_arttext.

Rocca Rivarola, M. D. (2013). Militando con el gobierno en tiempos de lazos políticos fluctuantes: Un estado de la cuestión como punto de partida para abordar la militancia oficialista en Argentina y Brasil desde Kirchner y Lula. Virajes, 15(1), 267-298. Recuperado de: http:/ /200.21.104.25/virajes/downloads/Virajes_15(1)completa. pdf\#page=267.

Rossi, F. (2017) La segunda ola de incorporación en América Latina: una conceptualización de la búsqueda de inclusión aplicada a la Argentina. En CAF (Ed.), Pobreza, desigualdad y política social en América Latina (155-194).Bogotá, Colombia: CAF. 
Springer, S. (2012). Neoliberalism as discourse: between Foucauldian political economy and Marxian poststructuralism. Critical Discourse Studies, 9 (2), 133-147. Doi: 10.1080/17405904.2012.656375.

Sader, E. (2009). El nuevo topo. Los caminos de la izquierda latinoamericana. Buenos Aires, Argentina: Siglo XXI Editores.

Schuttenberg, M. (2014).Las identidades nacional-populares, Villa María, Argentina: Editorial Universitaria Villa María.

Svampa, M. (2005). La sociedad excluyente. Buenos Aires, Argentina: Taurus.

UCA (2010). Informe del Observatorio de la Deuda Social Argentina 2009. Recuperado de: http://www.uca.edu.ar/uca/common/grupo68/files/ Barometro-de-la-Deuda-Social-UCA-Informacion.pdf.

Recibido: 21.01 .18

Aceptado: 10.04 .18 